\title{
Tumor Regression
}

National Cancer Institute

\section{Source}

National Cancer Institute. Tumor Regression. NCI Thesaurus. Code C160836.

A decrease in the size of a tumor or in the extent of cancer in the body. 